\title{
The Risk of Power Imbalance in Project Delivery: A Study of Large Victorian Public Infrastructure Projects
}

\author{
Hamzeh Zarei, Felix Kin Peng Hui, Colin Duffield \\ Department of Infrastructure Engineering, University of Melbourne \\ Parkville, Victoria, 3010, Australia \\ E-mail: hamzeh.zarei@unimelb.edu.au,kin.hui@unimelb.edu.au,colinfd@unimelb.edu.au \\ George Wang \\ Department of Construction Management, East Carolina University \\ Greenville, North Carolina, 27858, USA \\ E-mail: wangg@ecu.edu
}

Received 9 May 2017

Accepted 26 May 2017

\begin{abstract}
In large public infrastructure projects, political risks due to the power imbalance between central and delivery agencies are often overlooked or underestimated. The primary motive of the delivery agency in distorting information for political gains should be deemed a risk that creates uncertainty for large projects planning the outcome. In this study, seven large infrastructure projects in the state of Victoria, Australia are examined through a workshop involving key stakeholders who had played active roles in these projects. The findings revealed that power asymmetry between central and delivery agencies exist and would lead to optimism bias, which in turn creates uncertainty and risk of overpromising in the business case. Power asymmetry exist in large infrastructure projects because the central agencies usually only have the responsibility but not the skill set needed to measure the robustness of the business case. These types of political risks are difficult to quantify and even detect. This paper recommends a few managerial strategies that have referential values and/or can be used to mitigate and circumvent this risk.
\end{abstract}

Keywords: Political risks, Power asymmetry, Infrastructure projects

\section{Introduction}

Risk assessment is an essential part of an organization's strategic planning process. In aiming to achieve its strategic objectives, risk evaluation in the strategic planning process normally calls for some risk reporting taking into account normal and worstcase scenarios. Managerial decisions are then formed, and a risk management framework developed to retain a "no surprise" project operation status. Risk evaluation is also a vital part of project portfolio selection when a project is appraised for the risk and value in comparison to other initiatives. Due to limited resources, only the best value for money should permit to proceed, and hence robust risk assessment is a critical step in short listing and choosing the projects for investment.

Risk can come in the form of external and internal risks. External risks are the risks caused by elements external to the organization such as economic downturns and natural disasters. Traditionally a special category of external risk known as political risks specifically, have been largely ignored and only considered informally by project managers. Examples of political risk include external disruptive behavior that can deeply affect project cost, time and performance. However, it was difficult to quantify political risks due to their ever-changing nature. A common practice for accounting this type of risks would be to use an activity-based costing technique that increases the variance while estimating the performance of the activities in the project. However, this method is not robust or sufficient; probabilistic risk analyses may be better options to deal with political risks.

The specific aim of this research is to explore and investigate political risks in large infrastructure 
projects using cases of large Victorian public infrastructure projects as our basis for examination.

\section{Literature Review}

\subsection{Accounting for Political Risks - Past Studies}

Previous research in this area includes the Neelum Jhelum Hydroelectric Project (NJHP) (Kiani, 2014; Mukhtar, 2013). In this study, the authors tried to evaluate whether project managers working on large infrastructure projects in a volatile environment can have sufficient objective information in order to be able to utilize any form of risk modeling techniques.

The political risk is defined, in the study as any changes resulted from the hierarchy of control that alters the expected outcome and value of a given economic action by changing the probability of achieving business objectives. This massive infrastructure project is carefully chosen using Flyvberg's (2016) argument that a carefully chosen experiment, case or experience can lead to the critical situation, where one case may be able to provide sufficient evidence to justify an argument.

Neelum-Jhelum Hydro Power Plant (NJHP) is a run of the river hydroelectric generation project that is located in the vicinity of Muzaffarabad in the territory of Azad Jammu and Kashmir (AJ\&K) in Pakistan. This megaproject diverts the Neelum river water through a tunnel, into a powerhouse and out into the Jhelum River. The project experienced significant delays, funding issues and political disputes with regards to the Indus River Treaty signed between India and Pakistan.

Based on the detailed project study and the specific project accounts, twenty political risk factors were found for the NJHP - some of which had caused an effect on the cost, time and performance. Objective project information was then obtained to model these risks using a probabilistic model. The probabilistic risk assessment utilized two core principles: the principle of decomposition and Bayes probabilistic principle. It was outside of the scope of this research to determine the presuppositions and conditional probability data for a full set of scenarios and the posterior probability of the identified risks. By implementing the probabilistic model and costs derived for each of the identified risks, a total amount of approximately \$596 million USD was determined to be the impact of the identified risks on the $\$ 5$ billion USD project.

So were the managers able to obtain all the relevant objective data to run the probabilistic models? A closer look revealed that the majority of the information was derived from experts, who were on-site and had been on the project since its beginning.
An analysis of the impact of subjectivity in the data provided by experts showed that the probabilistic model loses its robustness and ability to assist project managers in real life - shown in the study by implementing a small change to conditional probabilities during the different design phases, resulting in a change of over $\$ 250$ million USD of cost variance.

The answer to the research problem is that, although conditional and a priori, the probabilities were being determined with experts are at best a guess - simply due to the nature of political risks. The authors then went on to conclude that the vast majority of objective data, such as costs, delays and impacts can be obtained objectively for the use of a probabilistic model to predict the impact to a project from political risks, the requirement of conditional and prior probabilities from expert opinions cannot be considered objective data, resulting in a model that may or may not be entirely realistic.

\subsection{Agency Theory Revisited}

Agency theory (Mitnick, 1975) attempts to explain the relationship between principals (defined as the entity with control over resources and legitimacy to make a decision including approval of a proposed solution) and the agent or the contractors (defined as a delegate of the principal to perform a task). The agent is expected to have knowledge and skills to explore the need, identify the solution and implement the work with the highest value for the principal and is also supposed to offer a solution for principal's approval. Eisenhardt (1989) provided an overview of the Agency theory by stating that principal-agent relationships should reflect efficient organization through information sharing and risk-bearing costs. Key assumptions are made about human nature being self-interest, bounded rationality, and risk aversion. The gap of information and incentive between principal and agent results in problems such as risk sharing, relationships with differing goals and risk preference.

The focus of the theory is determining the most efficient contract governing the principal-agent relationship given assumptions about people (e.g., self-interest, bounded rationality, risk aversion), organizations (e.g., goal conflict among members), and information (e.g., information is a commodity which can be purchased). Agency theory assumes the pursuit of self-interest at the individual level and goal conflict at the organizational level (March, 1962). In both perspectives, information asymmetry creates a power in the lower order participants (Pfeffer\& Pettigrew, 1976). Agency theory is a kind of information processing approaches that assumes 
individuals are rational and that information is distributed asymmetrically throughout organizations contingency theory (Chandler, 1962; Galbraith, 1973; Lawrence \&Lorsch, 1967). In political models, goal conflicts are resolved through bargaining, negotiation, and coalitions however in agency theory they are settled by the co-alignment of incentives using the price mechanism (Eisenhardt, 1989) or reward power in the contractual framework.

Agency theory is most relevant in situations in which contracting problems are difficult. These include situations in which there is (a) substantial goal conflict between principals and agents, such that agent opportunism is likely (e.g., owners and managers, managers and professionals, suppliers and buyers); (b) sufficient outcome uncertainty to trigger the risk implications of the theory (e.g., new product innovation, young and small firms, recently deregulated industries); and (c) unprogrammed or team-oriented jobs in which evaluation of behaviors is difficult (Eisenhardt, 1989). In some cases, it is difficult or expensive for the principal to verify what the agent is doing or whether the agent has behaved appropriately.

There is also a problem of risk sharing which arises when the principal and agent have different attitudes toward risk, and this results in different actions (Eisenhardt, 1989). Agency theory broadened this risk-sharing literature to include the agency problem that occurs when cooperating parties have different goals and division of labor (Jensen \& Meckling, 1976; Ross, 1973).

Researchers are divided on the usefulness and application of the Agency theory. Jensen (1983) argued that agency theory provides an important foundation while others have argued that the theory address no clear problem, is narrow, lacks testable implications, and is dangerous (Perrow, Reiss, \& Wilensky, 1986). Agency theory has been critiqued to having only a view of the world that ignores the complexity of organizations. Another view states that agency theory provides a unique, realistic, and empirically testable perspective on problems of cooperative effort (Eisenhardt, 1989).

\subsection{Power}

Being identified as a universal driver (Nietzsche, 1968), Power is a fundamental concept in political science (Falkemark, 1982; Isaac, 1987). A common definition of power comes from the causal relation between two entities one desires to influence, and one is affected (Isaac, 1987). "Power is the ability of those who possess it to bring about the outcome(s) they desire" (Salancik \& Pfeffer, 1974). Such power could extend over a broad span of means and leverage embedded in an actor's potential activities, called power field (Kurt Lewin, 1935). According to Raven (1993), Lewin (1952) defines power as the ability to induce forces' of a certain magnitude on another and is a fundamental phenomenon to explicate actors' behavior during interactions. Power is defined as the capacity to influence the conduct of others. It comes with exclusive access to resources less available to other e.g. access to information, knowledge, skills and expertise.

The classic theory of power identifies expert power, reward power, referent power, legitimate power, and coercive power as the basis of power (French \& Raven, 1959). The model was then completed by informational power as the sixth bases of power (Raven, 2008). Power aims to explain the intention of the powerful in changing the behavior of others. It originates from information, knowledge, skills, expertise, and ability to reward/punishment, rightful position, reputation and force. Means of exertion of power are diverse and changes according to the base of power.

Although the theories of power have been cultivated in the context of political science, it explains the means of compliance and influence in social systems (Dahl, 1957; Falkemark, 1982; Isaac, 1987; Lukes, 1974). In behavioral compliance or 'Decisionist' view “A has power over B to the extent that A can get B do something that B would not otherwise do" (Dahl, 1957). When power is viewed as a 'Non-Decision' Influence or an invisible influence (Szalai, 1997), there will be "mobilization of bias". Bias emerges when something favors a few, but suppress others (Schattschneither, 1960). "[mobilization of bias is] is a set of predominant values, beliefs, rituals, and institutional procedures that operate systematically and consistently to the benefit of particular groups and persons at the expense of others" (Szalai, 1997).

Pfeffer (2005) also distinguishes power from authority. In his view, power suggests hard power that its exertion diminish it, while authority is a legitimate position that might even reinforce when applied (Pfeffer, 2005). It could be said that authority is a power sourced from legitimacy and strengthened by reward and punishment. Nevertheless, the classic theory of power identifies and clusters the origin of power that explains the influence of actors more cohesively that acknowledges the variety of bases of power. We take the classic theory of power as the cornerstone of our research.

Measurement of power is controversial and problematic as the precise measurement is not possible (Pfeffer, 2005). When used between a pair of entities, power is a relative term. It does not exist in solitude. That is to say, the power of a powerful 
resonates with the perceived picture of others. In a relationship between a principal and an agent, the perimeters of their behavior will set the scope of power that each party might have over the other. Not only the conduct of actors may severely change under observation, but a proper study also requires two sets of data for actor behavior when power exerted and when power not exerted that is hard to structure and collect.

\subsubsection{Power in Project Delivery}

In a project, stakeholders have a different level of influence to impact the project (Cleland \& Ireland, 2007). Stakeholder salience theory considers power an indicator of the stakeholder influence (Mitchell, Agle, \& Wood, 1997). Kernaghan (1993) defines stakeholder relation to a project "a relationship involving sharing of power, work, support and information with others for the achievement of joint goals and mutual benefits". The participants' ability to influence the project decision-making process is laid in their power comprises proficiency as well as influence.

The term 'powerful' in projects also implies competency, skillfulness, expertise, experience, qualification and adequacy. A knowledgeable consultant has an impact on a client, and a skilled contractor has the power to demand a higher price. In projects, power is not only perceived as the ability to change other's decision but the competency that convinces others to comply. That is to say; power is a combination of authority and competency in project systems.

A right mix of project people competency and motivation moreover to well-empowered project parties have a significant effect on success (Ayas, 1996; Nagadevara, 2012). That is to say, participants' power has a great role in project outcome through the effect it has on their communications and collaborations within the project that is reflected in their decisions.

The classic theory of power recognizes knowledge, skills, reputation, reward, legitimacy and coercion as origins of power. We try to map the six sources of power classic theory to authority and competency as the major pillars of power in projects. Authority resonate legitimacy, reward and fuels coercion power. On the other hand, competency relates to knowledge and skill power. It is rather puzzling how to associate reputation, as a source of power, with authority or competency. Reputation is not an actual characteristic but a perceived effect on others in a long-term collaboration. Reputation or referent power as means of influencing decision should be investigated in the context project delivery to explore cause and effects of any possible risk it may impose on the project actors' behavior.

\subsubsection{The Concept of Power Asymmetry}

There is a link between the utility of decisions and the cognition reflected in the level of knowledge and required resources to make an informed choice. Besides, there is no guarantee that the degree of authority and cognition in participants are in the balance when the opposite is suggested by literature when relates the irrationality to power (Flyvbjerg, 1998). Power has been blamed for being the cause of optimism bias (Inesi, 2010; Tost, Gino, \& Larrick, 2012), over-confidence (Fast, Sivanathan, Mayer, \& Galinsky, 2012), constraint ignorance (Lammers, Gordijn, \& Otten, 2008), and lack of advice taking (See, Morrison, Rothman, \& Soll, 2011). Actors' power in a project should be investigated as it originates the behavior and hence the quality of decisions.

Participants' power is an undividable part of any project, and its role should not be overlooked in project success. While power is the ability to influence other's decision, it is the capacity of one to fulfill the allocated task. Power asymmetry or imbalance exits when one party has more power than its working partners. In projects, a lack of in-house knowledge in public sector was a serious problem that contributes to time and cost overrun (Patel \& Robinson, 2010). Competence is a collection of knowledge, attitude, skills, and experience needed to successfully perform a function (International Project Management Association, 2006). Participants have a different level of competency in a project. Inappropriate level of competency hinders effective communication, cooperation and flexibility to change; new ideas are ignored, and collaboration is diminished. A possible extreme scenario is where project clients have supreme authority but inadequate resources to make an informed decision. The gap between participants' authority and competency prevent an optimum utilization of resources or maximized decision. The outcome would be a 'limited' decision (Sanderson, 2012) that occurs where either all options are not identified, or the best possible option is not preferred amongst them.

\subsubsection{Power in Central Government and Delivery Agencies}

Central agencies in government organizations typically only have executive powers to implement and enforce governmental decisions. Central agencies may or may not have the expertise to decide and the control of resources at the grassroots level or the delivery level. It is the essence of delegation process 
that a principal asks agencies to do a task that requires ad-hoc skills and knowledge. The central agency finds it inefficient and burdensome to keep all the necessary resources in-house but instead, to breakdown the work and allocate it to delivery agencies. Nonetheless, in a delegation, an implicit form of influence exists within approval process. Informal power is thought to be held by delivery agencies due to the knowledge, expertise and referent power the delivery agency has over the central agencies that will influence the approval of the proposed business case. There is, therefore, an element of exposure to the risk arising from the informal power that resides in these delivery agencies.

A closer look at the arrangement reveals that the power balance may influence information flow, decision making and dynamics between policy makers and project delivery team. While the central agencies use the business case as a means of evaluating the value of an investment proposal over other candidates, the robustness of the business case becomes important as it may influence the selection process. That is to say; delivery agencies may affect the content of business cases which is the primary form of information flow used for decision making. It is a critical risk if the business case may be made to look more optimistic to push the project through the initial approval gates.

Power comes from the delivery agencies close interaction and engagement with two first groups of agents: (a) Users i.e. these are the people who finally use the infrastructure; (b) Market i.e. these are the individuals or groups who design, who constructs and who supplies parts and components to bring the project to fruition. The superior knowledge of a delivery agency of user's requirements and market condition provide higher information power to delivery agencies in its communication with central institutions. Being close to the users and market brings a particular type of advantage in that the delivery can choose to withhold information from the agency or embellish the information or even to distort the information to their organization advantage or to enhance their positions. Although they are expected to act on behalf of the central agency, organizational need for survival and their ignorance of the government priorities of resource allocation may make them a bias toward their proposed business case. The approval process inevitably faces a risk of optimism in a proposed business case where the central agencies rely on a delegation process of delivery agencies prepare and propose a business case in line with government strategies. In effect, acting on behalf of a higher authority brings about the risk of optimism bias and over promising in proposed business case that might lead to opportunity loss or lesser value for money.

\section{Research Method}

In the first part of this research, publicly available parliamentary interviews with experts from government and private sector were indexed and analyzed to find the current challenges in the delivery of public infrastructure. The analysis allowed the root causes of the current shortcomings to be uncovered. Grounded research method and case study are used to assess the risk of over-promising in Victorian infrastructure delivery.

We incorporated focus group discussions to capture the process of decision making in the different stages of a project. A focus group discussion was then organized. The participants for the workshop were drawn from the people from the public and the private sector in Victoria. The aim of the seminar was too organized to fine-tune and validate the previous findings. During the workshop, the identified challenges, causes, and recommendations are presented and discussed. The workshop was held in March 2015 at a convenient location at a University premise. Forty-four experts were contacted via telephone, 26 were formally invited, 19 expressed their interests, and finally, 17 attended the workshop. Table 1.a shows the affiliated sector of the seminar delegates and Table 1.b depicts their depth of knowledge of the case study.

During the workshop, the experts' feedback was collected in every step. At the same time, seven case projects were presented, and learning lessons are solicited. The workshop was conducted by a professional moderator. Specialized software was used to capture the Expert's statements (recording was evaded to encourage candid disclosure of participants).

\section{Findings}

The workshop reviewed seven Victorian case projects. Project approval process is considered in a broader framework of central and delivery agencies. In an extension to the literature of organizational theories e.g. agency theory, the research splits up central and delivery agencies. It provides a better understanding of the current state of public procurement and highlights the existing organizational challenges such as asymmetry of power and conflict of incentives. The findings verify that underestimating the overpromising behavior of project delivery agencies during the planning stage of infrastructure is a critical risk that would impact the perception of success. It is postulated that the risk of 
Table 1.The demography of the workshop delegates

\section{a. Affiliated sector; $\boldsymbol{b}$. Knowledge of the studied project} cases

a.

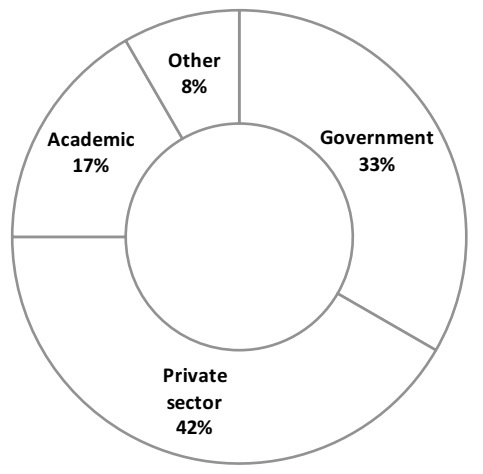

b.

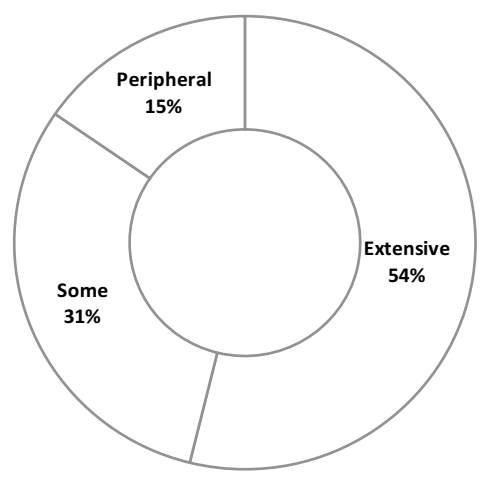

optimism bias could be attributed to the power balance of the participants. Power imbalance or asymmetry can be linked to the present shortcomings in public infrastructure by uncovering the people's behavior within project processes.

Whereas the common understanding of the literature implies that success is an outcome of project performance according to the plan, the majority of participants, $58 \%$, believe that success is mainly measured in the shadow of the initial expectations. More remarkably, $64 \%$ of experts find inflated expectations the leading cause of disappointment in projects. Optimism bias in planning the value and overpromising behavior of sponsors are the key factors in deterring a project from success.

The findings also endorsed the risk of overambitious decisions particularly those made of a business case. The quality of the business case is severely affected by client's fallacy of initial estimations especially if exaggerated benefits or optimistic cost are prime considerations. Many other factors were also found to be a possible cause of the over-promising behavior. The insufficient understanding of requirements, errant assumptions, inadequate technical knowledge, strategic misrepresentation and insufficient supervision are identified as leading factors that might cause a project bite off more than they can chew. The workshop outcomes confirm the initial hypothesis that the distribution of power among participants explains the risk of bias in preparing a robust business case.

Suboptimal decisions are partially attributed to the participants' conflicting interests when concurred with asymmetrical power. There is a risk of overpromising business case when resources are constrained and governed by central agencies, but the field knowledge of user requirements and market data rest with the delivery agencies. If the central agency is less informed of the decentralized project requirements, the risk becomes more severe.

\subsection{Informal Authority}

In this research, the notion of informal authority is conceptualized to explain the agency's referent power to manipulate and influence principal's decision. Informal authority contrasts the formal authority, a known legitimacy power of an entity that possesses it lawfully as a form of authority to make a decision. In public delivery system, the central agencies have the formal authority because of their given position in the approval process such as gateway review. Central agencies allocate resources and control the progress. Conversely, informal authority is a tacit power possessed by an entity, usually a subordinate or a reporting organization. In other words, informal authority influences a formally authorized entity's decision. In projects, the informal authority may originate from information, expertise or reputation power of an agency to manipulate other organizations' behavior. Every time a business case is found trustworthy the reputation of the delivery agency increases. The more the reputation of the delivery agency, the more the informal authority due to the increase of reputation power. As a conclusion, the concept of informal authority is relevant to the organizational challenge of Victorian public delivery, and so it is embedded in the theoretical framework of our proposed theory.

\subsection{Power and Optimism Bias}

The intrinsic worth of power asymmetry theory is cross-checked against seven recent case projects in Victoria. These case studies are selected across the extreme range of performance. Through a series of questions, the participants evaluated the level of success whereas informal authority.

Failure is measured through questioning the experts of the gap between expectations and 
outcome. It shows a mix of perceived success and failure among the case studies. The popular projects in the eyes of experts are Convention Centre, Children Hospital, and Regional Rail Link. On the opposite, Myki, HealthSMART and Market Relocation are deemed disappointing; finally, Victorian Desalination is in limbo.

It was found that informal authority exists among the central and delivery agencies. It is partly due to the governance structure frequently adopted in Australia where delivery agencies are delegated to communicate the field data. The role of central agencies is merely direct and audit. The information gap and distribution of skills among central and delivery agencies creates an informal authority for the delivery agencies that might create a risk to the project. It appears that if a delivery agency has an accurate understanding of the requirements, risks may be minimized; see Children Hospital. The contract structure of Children Hospital project is PPP (Public Private Partnerships) that allocate the risk of cost overrun and time delay to the private sector. The procurement strategy for this project plays an active role to provide a robust project estimation. A solid understanding of the project and user requirements provides unswerving information to the central agency to make a decision that preserves value for money. An adequate understanding of the requirements, make a client an informed buyer that profoundly contributes to project success.

In the view of stakeholders and experts, the risk of informal authority and failure are connected. The correlation factor of 0.71 shows that the higher informal authority, the greater risk of a failure; see Figure 1.

The data shows that informal authority is not unavoidable nor does it always lead to a failure. However, it might be suggested that there is a threshold that beyond which the risk of manipulation is high and the disaster is probable e.g. Myki and HealthSMART. Within the threshold level, the central agencies' understanding of the requirements is a key to defusing the threat of informal authority.

Informal authority if not managed through another mechanism of informing the decision maker e.g. proper procurement strategy, will cause risk of failure. Among the case studies, those show high informal authority are ended with a perception of failure.

\section{Discussion}

\subsection{Sense of Power Contribute to Optimism Bias}

In our study of Victorian large infrastructure projects, we recognized the peculiar role of Central agencies

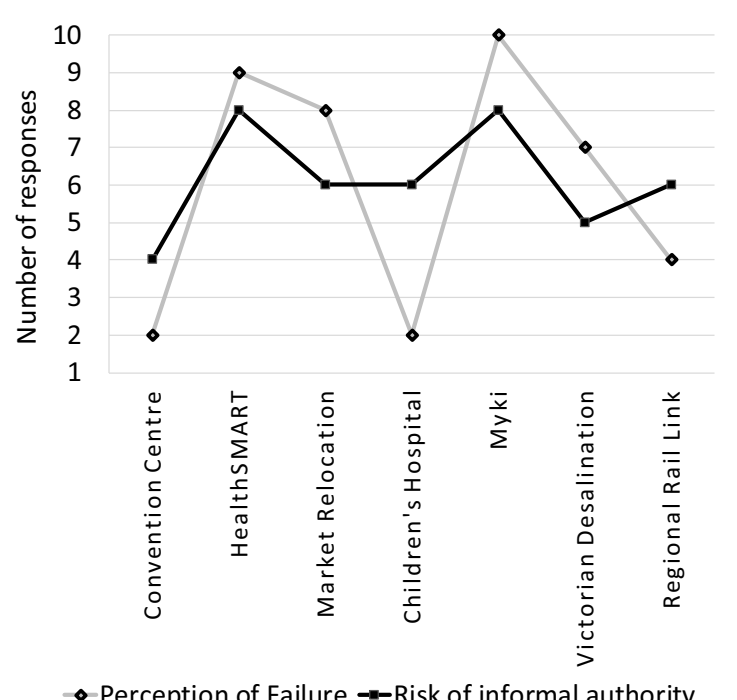

Figure 1. Informal Authority vs. Failure in seven Victorian infrastructures; Correlation factor $=0.71$

that hold the formal authority and approved the funding for proposed project i.e. the Cabinet and the Treasury, or retrospectively audit project delivery process i.e. the Parliament and Auditor-General that provide specialized audit and reports to the central agencies. Central agencies make the final decision and tend to have an over-reliance on the delivery agencies for developing a business case.

The delivery agencies, on the other hand, are expected to have field knowledge while being in relation with end users and market entities. They initiate or develop a business case for the central agencies that compete for the limited funding and approvals. The race for limited resources provokes informal authority that raises the power of the delegate in swaying the final decision. The relationships between the agencies are depicted in Figure 2.

The issue of informal authority introduces risk into the system as central agencies do not have the first-hand information and expertise. Emerging power is masqueraded in this informal authority as the delivery agencies now have influence over final approval decision through manipulating the quality of the business case. They have the power to make the business case optimistic and more appealing to the central agencies either intentionally in a strategic misrepresentation of swaying the approval process or unintentionally as a result of a psychological process of discounting worst case scenarios or absence of realistic assumptions. 


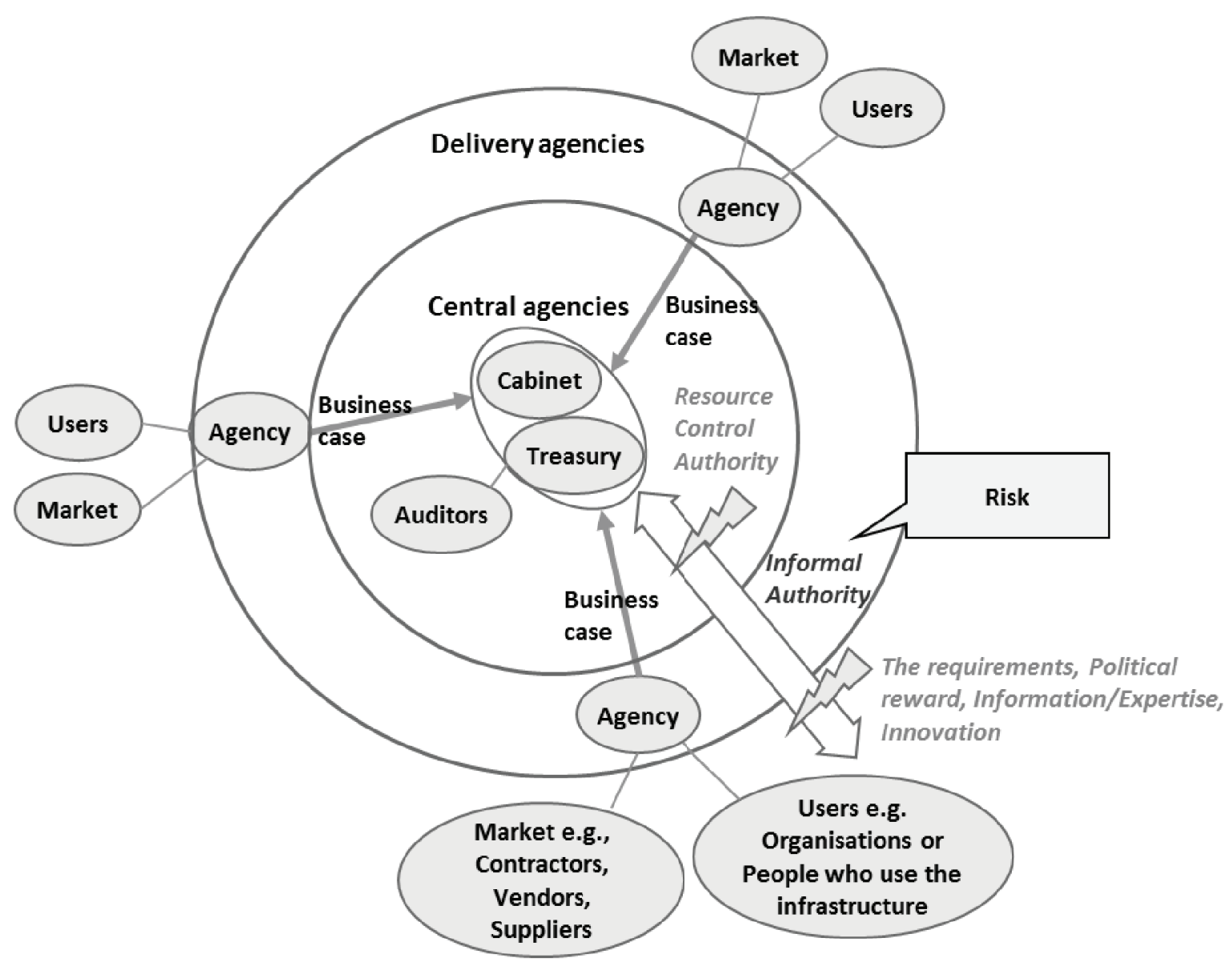

Figure 2. Power fields of public agencies in infrastructures delivery systems.

\subsection{Uncertainties and Risks Arising}

Uncertainty risk stems from one party holding more power and influences others. These results in the uncertainty (risk) those results in 1) an overpromising behavior and 2) under-delivering when constraints cannot be overcome. Due to the lack of knowledge and expertise, central agencies may not have a sound check and balance system in place as they cannot control due to not physically present all the time. Secondly, they are continually relying on the delivery agency for information and advice.

When the business case is made too optimistic due to a motivation of getting initial project approval and funding, the chance of approval increases. It leads to a kind of overpromising behavior which introduces uncertainty and risk where resources are limited, and investment opportunities substitute each other.

\section{Managerial Implications and Significance of the Research}

Projects with a known boundaries and accurate estimation models, such as buildings, are less risky than those of complex interfaces with latent conditions such as IT, earthworks, or unpredicted market demand. Furthermore, a delivery agency with an on-going stream of projects accumulates experiences and gets a true understanding of the user requirements. That might explain why a department that routinely delivers hospitals has a higher chance of being successful, even if it has a medium level of informal authority. Nonetheless, informal authority remains a threat for early stage decisions particularly if the delivery agency is not an informed buyer. Even a reliable and positive record of a delivery agency in fulfilling expected value for money is not enough to assure the central agencies as it raises the reputation of the delivery agency that sources informal 
authority. A change in the approval process is required to deal with this uncertainty.

To mitigate this risk, different strategies to manage participants' risk of power asymmetry are proposed. Three strategies are found more effective to control the risk of planning fallacy by balancing the participant power. These strategies are detailed in subsections 6.1 to 6.3 below.

\subsection{State-wide Centre of Expertise}

Lack of adequate expertise in the public sector is a danger in infrastructure delivery. Not only there are examples of the public sector being incompetent in addressing the proper requirements of a project, but there is also a growing concern for managing and preserving the existing corporate memory.

Therefore, external expertise is preferred and called upon by the delivery agencies find outsourcing an efficient approach to access occasional skills. Consequently, lack of in-house expertise is more likely in the major one-off projects that require unique know-how normally non-existent in agencies' skill set.

Although it might not be efficient for every deliverer to keep a separate skill set, having a statewide center of excellence would be an answer that has been applied in other jurisdictions too e.g. Ontario, Canada as it engages in every large project on a frequent basis. A center of expertise is proposed. The aim of this center of expertise is to create knowledge, implement large projects, maintain public competency and accumulate the experience. Such a center will benefit delivery agencies as well as central agencies by providing a reliable benchmark in assessing the optimism in a business case.

\subsection{Stable delivery pipeline}

Although central public agencies have the authority, usually by people's election, to direct public investments, they are political entities with political gain as the motive and incentive. The appetite for political gain is a pitfall that might be abused if a business case targets to stimulate it by overpromising that intrigues central agencies for a higher political weight.

Public infrastructures are typically large, and their delivery cycle is likely to be lengthier than a political cycle. That is to say; a government might not last long enough to witness the end product of an incepted infrastructure. The longer life cycle of infrastructure delivery than political elections may create a risk of a government becoming bias toward early benefits of a project that could be projected as a political gain. Investment priorities and project pipeline are strategies to emphasize the long-term value of a project for the community.

A steady delivery pipeline has the advantage of retaining public skills in-house or helps outsource it more efficiently. A delivery pipeline provides ample opportunity for stakeholders to engage and share their requirements. A qualified public agency with sufficient understanding of user requirement has a higher chance of success. This is also true in the private sector where a reliable schedule of infrastructure facilitate skills management is beneficial. Private sector being already informed of the project queue, organize the necessary resources. It collectively increases competition and eventually benefits the community.

Even though it is accepted that a delivery pipeline should be kept away from short-term political influence, the legitimacy of a long-term isolated pipeline is under question too. An elected government set forward to fulfill the people's direct interests. It is easily conceivable that a plan of a voted government might be different to those of a long-term infrastructure pipeline. It remains to be investigated the optimum mechanisms of a government to influence the infrastructure pipeline.

\subsection{Early Engagement of Stakeholder through financial Commitments}

For some stakeholders, such as end users of an infrastructure, the first engagement might occur the first day of the project operation. That is to say; these secondary stakeholders feel no legitimate link, no urgency and no power to influence the project in the early days. Nonetheless, the impact they receive from the project is substantial. That might explain why social infrastructure is prone to create a controversy just close to the operation day.

Early engagement of dormant stakeholders may stimulate streams of communication that assist transferring the stakeholder requirements when the cost of change is reasonably low. Users may have less incentive to engage since they underestimate the value of early decisions, and also they are not contractually bonded with no authority to raise a voice. Infrastructure users should be given an opportunity to express their expectations and advise their requirements. This objective is likely if the stakeholder has the right and need of engaging with project process.

While fees traditionally start after the operation, infrastructure users might be summoned to discuss the payment regime long before the asset is delivered. A form of financial commitment ahead of product delivery would intrigue the stakeholder and attract 
their attention. This financial structure could be optimized to raise the voice of silent stakeholders.

Scope and requirements might change in early stage, or the investment might fail the test of feasibility, the early financial engagement of the stakeholders should carefully avoid to inspire any sense of guarantee to the project team and to hold ready a mechanism of snap back.

\section{Conclusion}

Governing a construction project includes many constituencies working together. Public projects are defined and proposed in the context of political interaction of government agencies and the private sector. Breaking down the government agencies into delivery agencies and central agencies may unravel the complexity of decision processes. The behavior of agencies in decision and approval process determines the quality of planning and ultimately the project outcome.

During the planning stage, a business case defines the project scope and conceptual design that affects the project perception of success in long term. While the quality of business case is the cornerstone of project success, optimistic plan often ends up with a perceived failure. The risk of influence over the approval process may hinder the government achieving the expected value for money.

Agency theory assumes an information and incentive gap between principal and delegates. The theory tries to explain shortcomings in the quality of early decisions when the agencies may not follow the interests of the principal as it would follow their own. In public infrastructure, early decisions are made by a business case that a delivery agency proposes to central agencies for review and approval. In the presence of misaligned objectives of agencies and unbalanced distribution of information, the delivery agency may manipulate the process in favor of its organizational preferences in preparing the business case such as scenario making and analysis, estimation of time and cost, identifying and analysis of project options, and selection of procurement strategy.

Power plays in any multiplayer settings. Power comes from an efficient access or exclusive control over relevant resources and is always a perceived concept rather than an absolute term. Principal's power is the ability to align the agent's action with the principal value vis-à-vis the Agent power is the ability to influence the principal decision. The classic theory of power identifies knowledge, skills, reputation, legitimacy, and force as sources of power. Authority and competence are the two axes of power in projects. Bringing the classic theory of power to the context of projects shows that reputation (or referent) is an informal power that emerges and develops in a long-term collaboration. We have proposed a concept of informal authority to explicate the risk of overpromising as a behavior that delivery agency exhibits during the approval process. In a visual framework that graphically illustrates the power field of project agencies, the dissimilar perspectives of central and delivery agencies are studied and the risks of making suboptimal decision investigated. It was observed that decision makers' power balance is a significance contributor to the quality of early decisions.

In a dedicated workshop attended by project associates, we collected stakeholders' perspective on seven infrastructure projects in the state of Victoria, Australia. The perception of failure and the informal authority are measured, and the correlation is indicated. Expectedly, informal authority exists across the case studies but remains benign when low or when the buyer is informed through other mechanisms such as procurement strategy. In the case of a significant informal authority, the risk of failure is high.

\section{References}

1. Ayas, K. (1996). Professional project management: A shift towards learning and a knowledge creating structure. International Journal of Project Management, 14(3), 131-136. https://doi.org/10.1016/ 0263-863(95)00080-1.

2. Chandler, a D. (1962). Strategy and Structure: Chapters in the history of American enterprise. Massachusetts Institute of Technology Cambridge, 349-407.

3. Cleland, D., \& Ireland, L. (2007). Project management Strategic Design and Implementation.

4. Dahl, R. (1957). The Concept of Power. Behavioral Science, 2(3), 201. https://doi.org/10.1002/ bs. 3830020303 .

5. Eisenhardt, M. (1989). Agency Theory: and Assessment Review. The Academy of Management Review, 14(1), 57-74.

6. Falkemark, G. (1982). Power, Theory and Value. CWK Gleerup.

7. Fast, N. J., Sivanathan, N., Mayer, N. D., \& Galinsky, A. D. (2012). Power and overconfident decisionmaking. Organizational Behavior and Human Decision Processes, 117(2), 249-260. https://doi.org/10.1016/ j.obhdp.2011.11.009.

8. Flyvbjerg, B. (1998). Rationality and Power: Democracy in Practice. University of Chicago Press.

9. Flyvbjerg, B. (2016). Five Misunderstandings About Case-Study Research. Qualitative Inquiry, 12(2), 219245. https://doi.org/10.1177/1077800405284363.

10. French, J. R. P., \& Raven, B. (1959). The Bases of Social Power. In D. Cartwright \& A. Arbor (Eds.), Studies in Social Power (pp. 150-167). University of 
Michigan Press.

11. Galbraith, J. R. (1973). Designing Complex Organizations. Organization development. https:// doi.org/10.2307/248839.

12. Inesi, M. E. (2010). Power and loss aversion. Organizational Behavior and Human Decision Processes, 112(1), 58-69. https://doi.org/10.1016/ j.obhdp.2010.01.001.

13. International Project Management Association. (2006). IPMA Competence Baseline. (G. Caupin, H. Knoepfel, G. Koch, K. Pannenbäcker, F. Pérez-Polo, \& C. Seabury, Eds.) (3rd ed.). International Project Management Association.

14. Isaac, J. (1987). Power and Marxist Theory. Cornell University Press.

15. Jensen, C., \& Meckling, H. (1976). Theory of the Firm: Managerial Behavior, Agency Costs and Ownership Structure. Journal of Financial Economics, 3, 305 -360. https://doi.org/10.1016/0304-405X(76)90026-X.

16. Jensen, M. C. (1983). Organization Theory and Methodology. The Accounting Review, 58(2), 319339. https://doi.org/10.2307/24683Kernaghan, K. (1993). Partnership and public administration: conceptual and practical considerations. Canadian Public Administration, 36(1), 57-76. https://doi.org/10.1111/j.1754-7121.1993.tb02166.x.

17. Kiani, K. (2014). Neelum-Jhelum Project Facing Financial Problems. https://www.dawn.com/News/ 1129742.

18. Lammers, J., Gordijn, E. H., \& Otten, S. (2008). Looking through the eyes of the powerful. Journal of Experimental Social Psychology, 44(5), 1229-1238. https://doi.org/10.1016/j.jesp.2008.03.015.

19. Lawrence, P. R., \& Lorsch, J. W. (1967). Organization and Environment. Organization and environment.

20. Lewin, K. (1935). A dynamic theory of personality. Journal of Heredity. https://doi.org/10.1109/ IEMBS.2008.4649489.

21. Lewin, K. (1952). Constructs in field theory [1944]. In Field theory in social science: Selected theoretical papers by Kurt Lewin (Vol. 191, pp. 30-42). https://doi.org/10.1037/10269-014.

22. Lukes, S. (1974). Power: A Radical View. London: Macmillan.

23. March, J. (1962). The business Firm as a Political Coalition. The Journal of Politics, 24(4), 662-678.

24. Mitchell, R. K., Agle, B. R., \& Wood, D. J. (1997). Toward a Theory of Stakeholder Identification and Salience: Defining the Principle of Who and What Really Counts. The Academy of Management Review, 22(4), 853. https://doi.org/10.2307/259247.

25. Mitnick, B. M. (1975). The theory of agency - The policing "paradox" and regulatory behavior. Public Choice, 24(1), 27-42. https://doi.org/10.1007/ BF01718413.

26. Mukhtar, I. (2013). NAB, PM Secretariat reluctant to take action. http://nation.com.pk/national/03-Jan2013/nab-pm-secretariat-reluctant-to-take-action.
27. Nagadevara, V. (2012). Project Success Factors and Inter-sectorial Differences. Review of Business Research, 12(1), 115-121.

28. Nietzsche, F. (1968). The Will to Power. New York (Vol.21). https://doi.org/10.1038/ scientificamericanmind0310-24.

29. Patel, M., \& Robinson, H. (2010). Impact of governance on project delivery of complex NHS PFI/PPP schemes. Journal of Financial Management of Property and Construction, 15(3), 216-234. https://doi.org/10.1108/13664381011087489.

30. Perrow, C., Reiss, A., \& Wilensky, H. (1986). Complex Organizations: A Critical Essay. Random House (Vol. 3). https://doi.org/10.2307/2062232.

31. Pfeffer, J. (2005). Understanding the Role of Power in Decision Making. In Classics of Organization Theory (pp. 289-303).

32. Pfeffer, J., \& Pettigrew, A. M. (1976). The Politics of Organizational Decision-Making. Contemporary Sociology, 5(4), 478. https://doi.org/10.2307/2063824.

33. Raven, B. H. (1993). The Bases of Power: Origins and Recent Developments. Journal of Social Issues, 49(4), 227-251. https://doi.org/10.1111/j.1540-4560.1993. tb01191.x.

34. Raven, B. H. (2008). The Bases of Power and the Power/Interaction Model of Interpersonal Influence. Analyses of Social Issues and Public Policy, 8(1), 122. https://doi.org/10.1111/j.1530-2415.2008.00159.x.

35. Ross, S. A. (1973). The economic theory of agency: The principal's problem. The American Economic Review, 63(2), 134-139. https://doi.org/10.2307/ 1817064.

36. Salancik, G. R., \& Pfeffer, J. (1974). The Bases and Use of Power in Organizational Decision Making: The Case of a University Gerald R. Salancik and Jeffrey Pfeffer. Administrative Science Quarterly, 19(4), 453473. https://doi.org/10.2307/2391803.

37. Sanderson, J. (2012). Risk, uncertainty and governance in megaprojects: A critical discussion of alternative explanations. International Journal of Project Management, 30(4), 432-443. https://doi.org/10.1016/ j.ijproman.2011.11.002.

38. Schattschneither, E. E. (1960). The Semi-Sovereign People. Dryden Press.

39. See, K. E., Morrison, E. W., Rothman, N. B., \& Soll, J. B. (2011). The detrimental effects of power on confidence, advice taking, and accuracy. Organizational Behavior and Human Decision Processes, 116(2), 272-285. https://doi.org/10.1016/ j.obhdp.2011.07.006.

40. Szalai, J. (1997). Power and Poverty. Social Research. New York: Oxford University Press.

41. Tost, L. P., Gino, F., \& Larrick, R. P. (2012). Power, competitiveness, and advice taking: Why the powerful don't listen. Organizational Behavior and Human Decision Processes, 117(1), 53-65. https://doi.org/ 10.1016/j.obhdp.2011.10.001. 